Jurnal Pemberdayaan: Publikasi Hasil Pengabdian kepada Masyarakat

Vol. 4, No. 3, Desember 2020, Hal. 339-346

ISSN: 2580-2569; e-ISSN: 2656-0542

DOI: https://doi.org/10.12928/jp.v4i3.2308

\title{
Pelatihan Pembuatan RPP Menggunakan Metode 4 C'S Bagi Guru-Guru MGMP Bahasa Inggris Kalimantan Selatan
}

\author{
Hafizhatu Nadia, Yansyah, Tenny Murtiningsih \\ Universitas Muhammadiyah Banjarmasin, Jl. S. Parman. Kompleks RS Islam, Pasar Lama, \\ Banjarmasin Tengah, Kota Banjarmasin, Kalimantan Selatan 70114 \\ Email: hafizhatunadia@gmail.com
}

\begin{abstract}
ABSTRAK
Pada saat ini, peserta didik diharapkan untuk memiliki keterampilan sosial dan personal abad 21, yaitu kreatifitas, kolaborasi, berpikir kritis, dan komunikatif karena keterampilan kognitif saja tidak cukup untuk menghadapi tantangan yang akan mereka temukan di masa depan. Hal ini kemudian menjadi tantangan bagi para guru untuk bisa mengintegrasikan keempat komponen tersebut dalam pembelajaran dalam kelas. Pertimbangan ini menjadi latar belakang pelatihan pembuatan Rencana Pelaksanaan Pembelajaran (RPP) yang diperuntukkan untuk guru-guru MGMP di Kalimantan Selatan. Pelatihan ini berupa workshop satu hari dimana para guru belajar mengenai konsep 4 C'S dan di akhir sesi pelatihan mereka diminta untuk berkolaborasi membuat RPP. Pada kegiatan kolaborasi ini guru-guru berdiskusi tentang suatu topik, menentukan langkahlangkah pembelajaran, sekaligus memikirkan dibagian mana mereka menyisipkan 4 C. RPP ditulis pada sebuah kertas karton besar yang kemudian akan didisplay dan dipresentasikan. Pada akhir kegiatan, peserta diminta untuk merefleksi apa yang telah mereka pelajari dan mengisi angket yang berisi persepsi dan evaluasi terhadap program pengabdian masyarakat ini. Peserta kegiatan merasa senang dan mendapatkan manfaat berupa praktik langsung pembuatan RPP serta berkolaborasi dengan rekan MGMP dari berbagai wilayah di Kalimantan Selatan.
\end{abstract}

Kata kunci: Pelatihan guru, Rencana Pembelajaran, Metode 4 C'S

\begin{abstract}
Nowadays, students are required to have the 21st social and personal skills. To achieve success in the future, learners can not solely rely themselves on cognitive intelligence, but there are other supporting skills such as creativity, collaboration, critical thinking, and communication skills they need to hone through education. With this in mind, these skills need to be integrated into learning process, particularly, during classroom interaction. Teachers play a central role in infusing the positif values of the skills. Therefore, this workshop is intended to train English teachers in South Kalimantan on designing a model of lesson plan called 4C's based learning. This workshop facilitates teachers to discuss about certain topics, formulating learning phases, and the ways to integrate the 4C's concept into learning materials. The lesson plan is written on a big poster and then presented in the classroom. At the end of the program, participants are assigned to do self reflection on what they have studied. They are also invited to respond to a survey regarding their perception and evaluation of the program. The workshop indicated the participants' satisfaction. The participants receive training on making a good lesson plan and can collaborate with other English teachers across South Kalimantan.
\end{abstract}

Keywords: teacher training, lesson plan, $4 C^{\prime}$ 's

\section{PENDAHULUAN}

Perkembangan teknologi pada jaman sekarang ini, tidak dapat kita pungkiri akan berpengaruh juga pada sektor pendidikan. Media pembelajaran yang awalnya hanya berupa papan tulis hitam dan kapur tulis perlahan berubah menjadi whiteboard dengan spidolnya, perlahan lagi berubah menjadi PowerPoint yang ditampilkan di layar LCD dengan warna, 
suara, dan visual. Seiring dengan perkembangan itu ada juga hal penting yang berubah, yaitu tuntutan dunia pendidikan kepada para peserta didik. Menurut Sukartono (2017) para peserta didik pada masa pendidikan 4.0 ini harus disiapkan dalam tiga hal, yaitu bisa bekerja untuk pekerjaan yang muncul di masa depan, menyesaikan masalah baru yang muncul di masa mendatang, dan memiliki keterampilan teknologi yang muncul nanti. Konsep pendidikan abad ke-21 juga menuntut sekolah agar bertransformasi dan bisa membentuk peserta didik menjadi lebih kreatif, mudah beradaptasi, bisa berkolaborasi serta melakukan inovasi karena kesuksesan mereka di masa mendatang dipengaruhi oleh faktor-faktor tersebut (Center, 2010).

Dalam pola kurikulum 13 disebutkan bahwa fungsi guru sebagai fasilitator dalam pembelajaran harus lebih banyak. Selebihnya peserta didik dibiarkan untuk bekerja sama, berkreasi sendiri dan mengembangkan sendiri sesuai dengan kebutuhan yang mereka perlukan. Guru harus berpindah dari pola teacher-centred menjadi student-centred. Interaksi antar peserta didik penting untuk menumbuhkan sikap percaya diri dalam berkomunikasi, kebutuhan untuk berkolaborasi, kemampuan memecahkan masalah bersama-sama, serta peningkatan kreativitas melalui kegiatan berbagi ide. Untuk menjalankan sungsi sebagai fasilitator, guru harus memiliki kemampuan yang baik dalam mendesain pembelajaran yang menuntut peseta didik aktif. Guru juga harus bisa menstimulasi agar semua peserta didik bisa ikut terlibat dalam proses pembelajaran. Oleh sebab itu, pengetahuan seorang guru terhadap berbagai jenis metode dan teknik sangat diperlukan ketika terjadi pergeseran pola pengajaran ini.

Dengan tuntutan yang sangat besar tersebut maka tidaklah heran pula apabila seorang guru juga dituntut untuk memiliki kompetensi yang optimal, sehingga bisa merancang dan mengarahkan pola pembelajaran yang sesuai dengan yang diperlukan oleh para peserta didik dimasa sekarang ini. Salah satu keterampilan yang harus dimiliki oleh seorang peserta didik dimasa sekarang salah satunya adalah yang di kenal dengan 4 C'S (Critical thinking, Creativity, Collaboration, dan Communication). Critical thinking adalah suatu keterampilan dimana peserta didik memiliki kemampuan untuk memahami, menemukan dan memecahkan permasalahan yang di hadapi dengan tepat (Zubaidah, 2018). Keterampilan ini diintegrasikan hendaknya di segala aspek pembelajaran. Creativity yaitu kemampuan memunculkan inovasiinovasi baru dalam pembelajaran (Rohmadi, 2018). Tidak hanya inovasi dalam bentuk tradisional, tapi juga dalam hal teknologi. Collaboration, semua hal yang diciptakan melalui inovasi-inovasi baru tadi terkadang memerlukan kerjasama dan kolaborasi dengan berbagai pihak untuk membentuk sesuatu yang lebih baik lagi. Dan hal inilah yang perlu di kembangkan dalam pola pembelajaran kita, dimana peserta didik dilatih untuk bekerjasama dengan baik, memalui Communication yang baik dan efektif. Dengan komunikasi yang efektif, maka segala permasalahan baik di dalam kelas ataupun di luar kelas dapat diselesaikan dengan baik, apalagi di jaman modern di masa sekarang ini (Butarbutar, 2019).

Beberapa penelitian tentang metode ini juga sudah banyak dilakukan, baik itu untuk pembelajaran bahasa ataupun di bidang ilmu lainnya. Salah satunya adalah penelitian yang dilakukan oleh Trisnawati, W dan Sari, A (2019). Penelitian ini bertujuan untuk mengembangkan modul Sosiolinguistics untuk Prodi Pendidikan Bahasa Inggris yang terintegrasi pada keterampilan abad ke -21 yang berfokus pada keterampilan 4 C'S. Penelitian ini mehasilkan sebuah modul ajar yang terintegrasi dengan keterampilan abad 21 yaitu keterampilan 4 C'S, modul ini berhasil untuk memberikan kesempatan kepada mahasiswa untuk bereksplorasi dalam menemukan suatu konsep dalam proses pembelajaran, selain itu modul ini juga memberikan kesempatan kepada mahasiswa untuk memberikan kesimpulan berdasarkan aktivitas dan masalah yang ada di dalam modul tersebut.

Di penelitian berbeda lainnya yang dilakukan oleh Nurhidayati \& Kustini (2018), metode 4 C'S digunakan untuk mengembangkan bahan ajar dalam kontek English for 
Specific Purposes (ESP) di perguruan tinggi vokasi. Dari penelitian ini didapatkan bahan ajar Bahasa Inggris yang terintegrasi dengan keterampilan abad 21 yang dikenal dengan istilah 4C'S yaitu communication, collaboration, creativity, dan critical thinking. Bahan ajar ini berhasil menyajikan materi ajar yang inovatif dan up to date, memberikan pengetahuan dan kesempatan kepada mahasiswa untuk mendapatkan materi ajar yang menarik dan sesuai dengan karakteristik peserta didik serta kemampuan berbahasa inggris mereka. Dari kedua penelitian ini menunjukkan bahwa metode 4 C'S efektif digunakan baik untuk pembelajaran maupun pengembangan materi ajar.

Dalam kurikulum 2013, peran guru sebagai fasilitator di dalam kelas mempunyai peranan yang penting dalam perencanaan dan pelaksanaan proses belajar mengajar. Guru memberikan stimulus kepada peserta didik untuk berfikir, berkreasi dan berkembang dengan sendirinya. Berbagai strategi dan metode pun bisa di pakai guru saat mengajar (Alawiyah, 2013). Perencanaan dalam pembelajaran yang disusun oleh guru merupakan langkah awal sebelum pelaksanaan proses belajar. Dalam pelaksanaan perencanaan ini guru akan menjelaskan setiap langkah yang akan dilaksanankan selama kegiatan di kelas. Mulai dari pre-activity, main activity dan post activit. Dari materi ajar smpai dengan bentuk penilaian, akan tertuang dalam pencana pelaksanaan pembelajaran (RPP).

Sayangnya tidak semua guru memahami atau mengenal metode 4 C'S ini. Meskipun beberapa kegiatan yang mereka laksanakan di kelas sebetulnya juga telah mengandung unsur $4 \mathrm{C}$ 'S tersebut tapi masih belum tersusun rapi atau menjadi tujuan dalam pembelajaran. Hal ini bisa dijembatani jika mereka mampu membuat rencana pelaksanaan pembelajaran (RPP) yang lebih terstruktur dan bisa memetakan letak-letak kemampuan 4 C'S dalam aktivitas di kelas. Ketiga pemateri yang merupakan dosen di Prodi Pendidikan Bahasa Inggris Universitas Muhammadiyah Banjarmasin berinisiatif untuk melakukan Pengabdian kepada Masyarakat (PKM) untuk memfasilitasi para guru mengembangkan metode 4 C'S. Pada akhir pelatihan, diharapkan para guru mendapatkan manfaat berupa peningkatan kemampuan menulis RPP dengan mengintegrasikan metode 4 C'S.

\section{METODE}

Kegiatan PKM ini dilaksanakan selama satu hari berbentuk pelatihan/workshop. Peserta kegiatan berjumlah tiga puluh enam guru bahasa Inggris yang berasal dari berbagai daerah di Kalimantan Selatan. Kegiatan dilaksanakan di Studio Adijani Al-Alabij, Universitas Muhammadiyah Banjarmasin. Diakhir kegiatan peserta diharapkan mampu membuat RPP dengan menggunakan metode 4 C'S secara berkelompok. Secara umum langkah-langkah yang digunakan dalam pelatihan ini adalah sebagai berikut:

1. Inisiasi, yaitu tahapan pemberian materi dalam bentuk ceramah dan diskusi. Ceramah pada sesi pertama yang bertujuan untuk menyamakan persepsi tentang seperti apa metode 4 C'S dan bagaimana penerapannya di dalam kelas. Seorang trainer dari Amerika Serikat, Yuta Otake, M.A., yang sedang berkunjung ke Kalimantan Selatan diundang untuk menyampaikan materi. Sesi ini berjalan kurang lebih selama dua jam.

2. Praktik pengembangan RPP. Pada sesi ini semua pemateri berperan sebagai fasilitator. Peserta dibagi menjadi kelompok yang terdiri dari 5-6 orang dan diminta untuk memilih satu topik materi yang nantinya akan dikembangkan dalam langkah-langkah pembelajaran. Pada tahapan ini pemateri mengarahkan peserta untuk mengambil topiktopik yang sesuai dengan tingkatan pembelajaran untuk kelas menengah pertama atau kelas menengah ke atas. Peserta kemudian diminta untuk menuliskan RPP mereka pada sebuah kertas karton besar yang akan ditampilkan di sesi presentasi.

3. Presentasi dan umpan balik. Semua peserta diminta untuk menempelkan kertas karton mereka pada dinding studio kemudian peserta lain diharapkan untuk berkeliling sambil bertanya dan memberikan umpan balik terhadap RPP kelompok yang didatangi. 
4. Evaluasi. Pada tahap ini peserta diminta untuk mengisi angket daring menggunakan Google Form yang bertujuan untuk mengetahui respon dan kebermanfaatan PKM bagi peserta.

\section{HASIL, PEMBAHASAN, DAN DAMPAK}

Kebanyakan peserta adalah guru-guru muda dengan pengalaman megajar kurang dari 5 tahun $(86,4 \%)$ persen. Sisanya adalah guru-guru senior dengan pengalaman mengajar lebih dari lima tahun bahkan ada satu dua yang telah mengajar belasan tahun namun masih semangat mengikuti pelatihan. Kebanyak peserta (45,5\%) merupakan guru sekolah menengah atas (SMA) dan sisanya adalah guru sekolah menengah pertama (SMP) dan satu orang guru sekolah dasar. Pada bagian ini akan diuraikan secara kualitatif dan kuantitaf tentang hasil pelatihan serta dampak bagi mitra PKM, yaitu guru-guru MGMP Bahasa Inggris Kalimantan Selatan. Data kuantitatif diambil dari respon peserta yang diberikan melalui angket. Namun, hasil angket tidak diambil dari jawaban semua peserta karena hanya 22 dari 36 peserta yang benar-benar menjawab dan mengumpulkan angket tersebut.

Pada sesi inisiasi pemateri menjelaskan tentang apa itu metode $4 \mathrm{C}$ 'S, urgensi, dan contoh aplikasinya di dalam kelas. Dibantu oleh Yuta Otake yang merupakan seorang English Native Speaker peserta terlihat antusias mendengarkan sekaligus praktik berbagai kegiatan yang bisa memicu 4 C'S (Communication Skill, Collaboration skill, Creative Thinking Skill, and Critical Thinking Skill). Melalui berbagai contoh kegiatan yang dilaksanakan mereka menyadari bahwa ternyata 4 C'S bisa diberikan untuk semua tingkatan peserta didik, bahkan untuk anak-anak. Kegiatan seperti menyanyi, mengganti lirik lagu bahasa Inggris, dan bermain ternyata bisa menjadikan kelas begitu hidup sekaligus mengajarkan keempat keterampilan tersebut. Kegiatan lain seperti diskusi, kerja kelompok, mengerjakan proyek, dan bermain peran adalah contoh aktivitas dalam kelas yang mampu menumbuhkan komunikasi dan kolaborasi antarsiswa, kreativitas, serta kemampuan berpikir kritis. Berdasarkan hasil angket diketahui bahwa 95.5\% peserta menyatakan bahwa materi yang disampaikan menarik sekali dan sisanya menyatakan menarik (Gambar 1).

\section{Materi sangat menarik}

22 responses

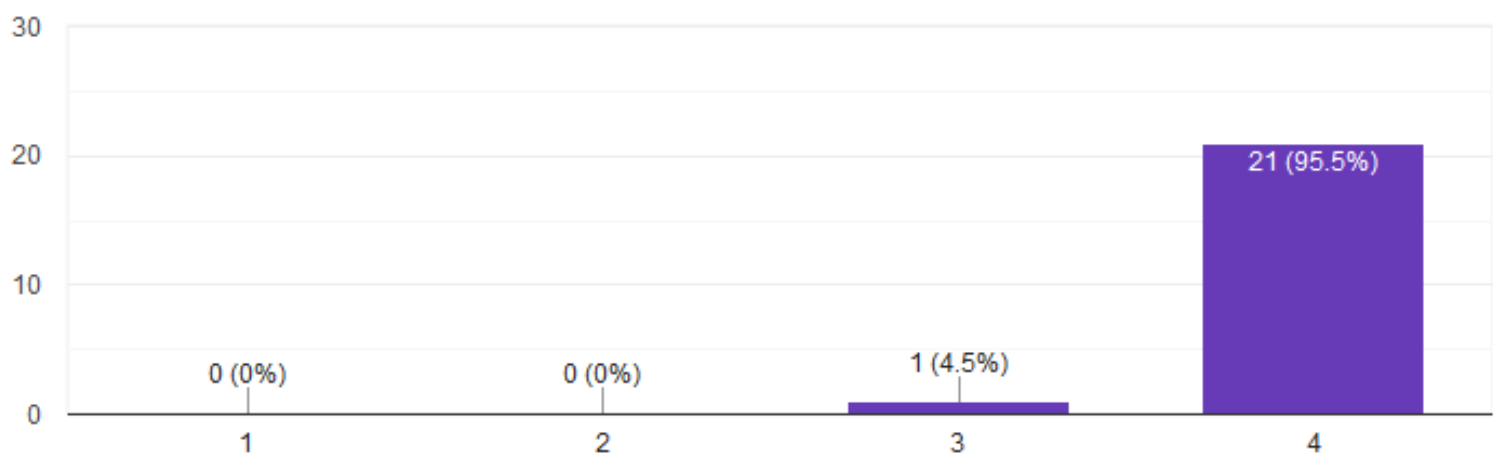

Gambar 1 Respon Peserta terhadap Materi PKM

Pada sesi praktik. Peserta dipersilakan untuk berkelompok yang terdiri dari lima sampai enam anggota. Pada tahapan ini peserta dibebaskan untuk berkreativitas. Pemateri hanya berperan sebagai fasilitator yang mengatur jalannya kerja kelompok dan membantu jika peserta mengalami kesulitan. Sebelum merancang RPP, peserta diberitahu bahwa mereka harus memuat tiga kegiatan, yaitu awal, tengah, dan akhir pelajaran. Peserta boleh memilih 
aktivitas dan tingkatan peserta didik yang diajar tapi mereka harus memasukkan unsur 4 C'S dalam RPP tersebut. Berdasarkan observasi pemateri, peserta menikmati kegiatan ini. Mereka larut dalam diskusi serta saling berbagi tentang aktivitas apa saja yang bisa dilaksanakan di kelas. Gambar 2 menunjukkan kerja sama peserta dalam menulis RPP yang akan mereka presentasikan. Kegiatan ini harusnya berjalan selama 30 menit namun peserta merasa bahwa waktu tersebut tidak cukup sehingga perlu ditambah hingga 45 menit.

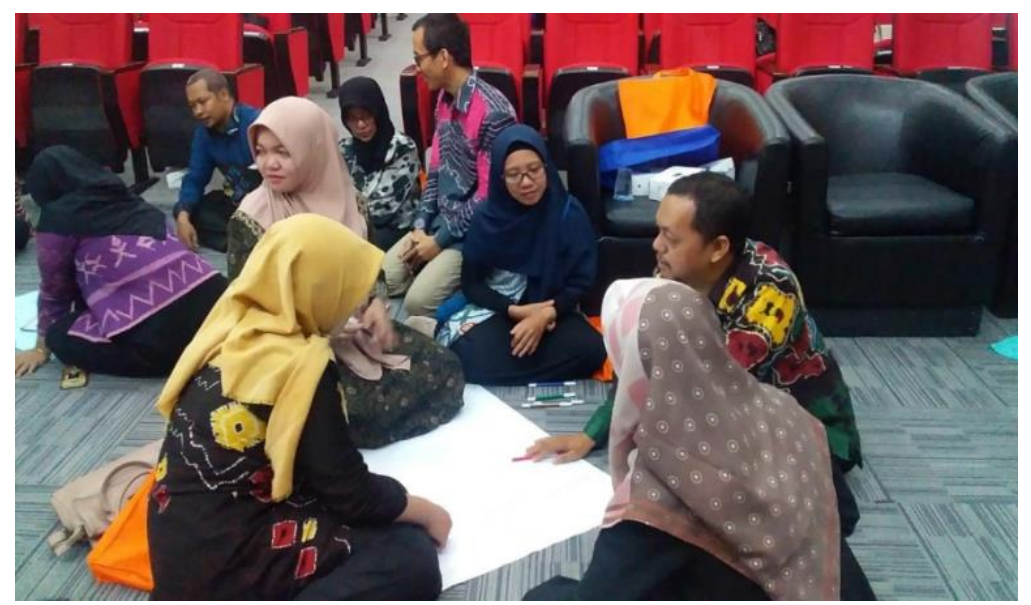

Gambar 2 Peserta Bekerja Sama ketika Praktik Pembuatan RPP

Sesi presentasi meminta peserta untuk menampilkan hasil karya mereka. Setiap kelompok menempelkan RPP yang telah ditulis pada kertas karton besar (Gambar 3). Pada tahap ini setiap anggota kelompok harus berbagi tugas. Ada satu sampai dua orang yang berjaga didekat RPP dan anggota lainnya akan berjalan dan melihat presentasi kelompok lain. Ketika berjalan, peserta melihat RPP dari kelompok lain, mendengarkan penjelasan, dan memberikan komentar sebagai umpan balik.

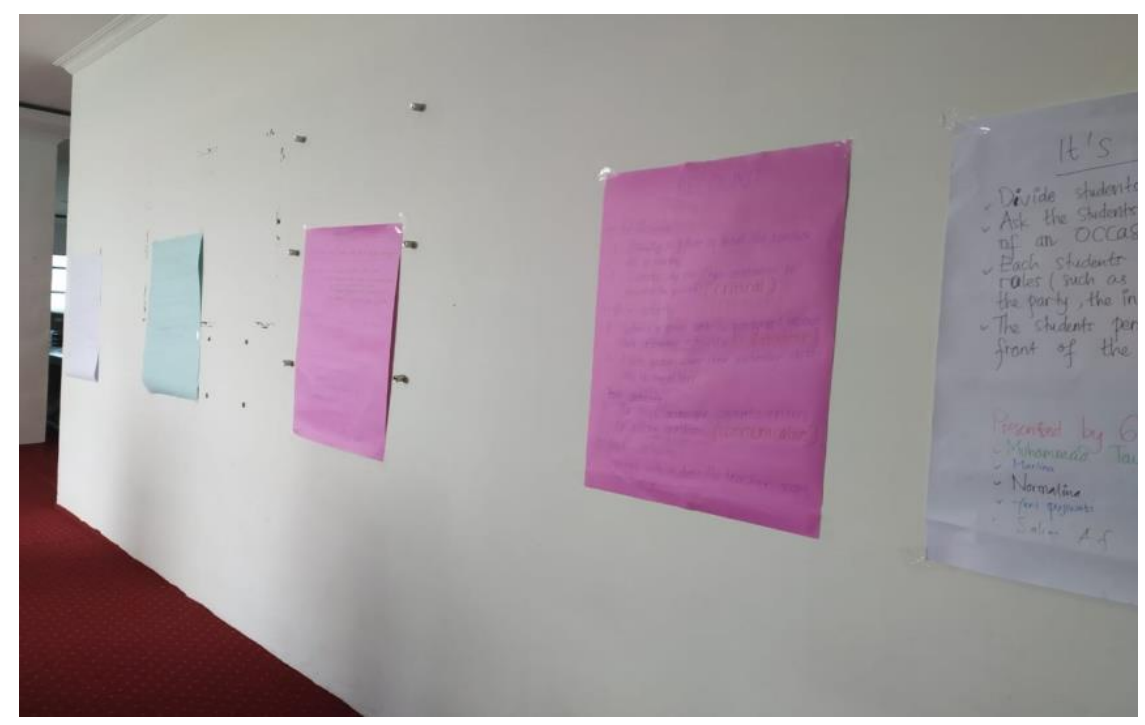

Gambar 3 Tampilan RPP yang Dibuat Peserta

Melalui kegiatan ini peserta mendapatkan kesempatan untuk saling bertukar ide tentang berbagai jenis kegiatan 4 C'S yang bisa mereka implementasikan di kelas. Hasil angket pada Gambar 4 menunjukkan bahwa 77,3\% peserta ingin sekali menerapkan RPP yang telah 
dipresentasikan baik oleh kelompok mereka sendiri atau kelompok teman di kelas mereka nantinya.
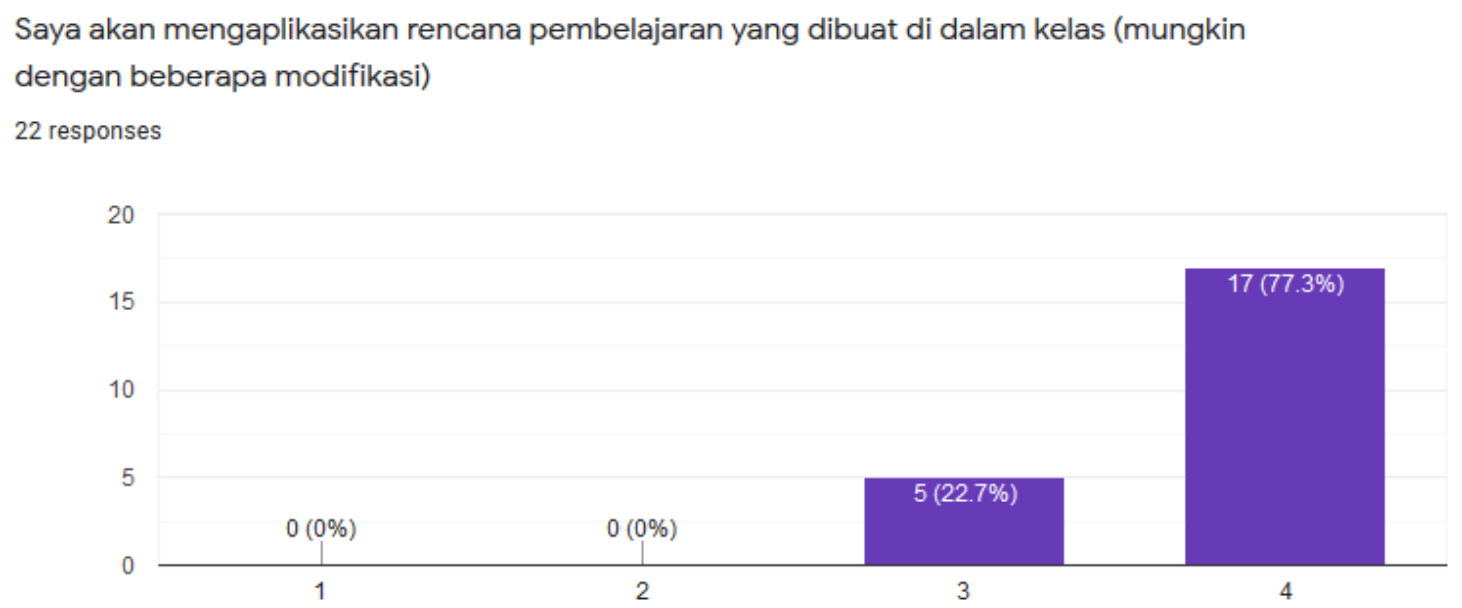

Gambar 4 Keinginan Peserta untuk Mengadopsi atau Adaptasi RPP yang telah Dipresentasikan

Terakhir, evaluasi terkait kebermanfaatn kegiatan PKM terhadap guru dipresentasikan pada Gambar 5 yang menyajikan data bahwa $86.4 \%$ peserta merasa kegiatan ini memberikan dampak positif bagi mereka. Mereka mendapatkan kesempatakan untuk mengembangkan profesionalisme melalui tambahan wawasan tentang metode 4 C'S sekaligus praktik penulisan rencana pembelajaran yang nantinya mereka bisa diaplikasikan di kelas. Sebagaimana yang dikemukakan oleh Alawiyah (2013) sangat penting bagi guru untuk bisa menemukan peran yang tepat didalam kelas. Kurikulum saat ini menuntut peserta didik untuk menjadi lebih aktif. Pengetahuan terkait metode 4 C'S serta cara pembuatan RPP ini diharapkan benar-benar dibawa oleh para peserta sampai dikelas mereka. Diharapkan, mereka bisa terus berkreasi agar peserta didik kita menjadi lebih komunikatif, kolaboratif, kreatif, dan kritis sehingga kualitas pendidikan di Indonesia menjadi semakin maju.
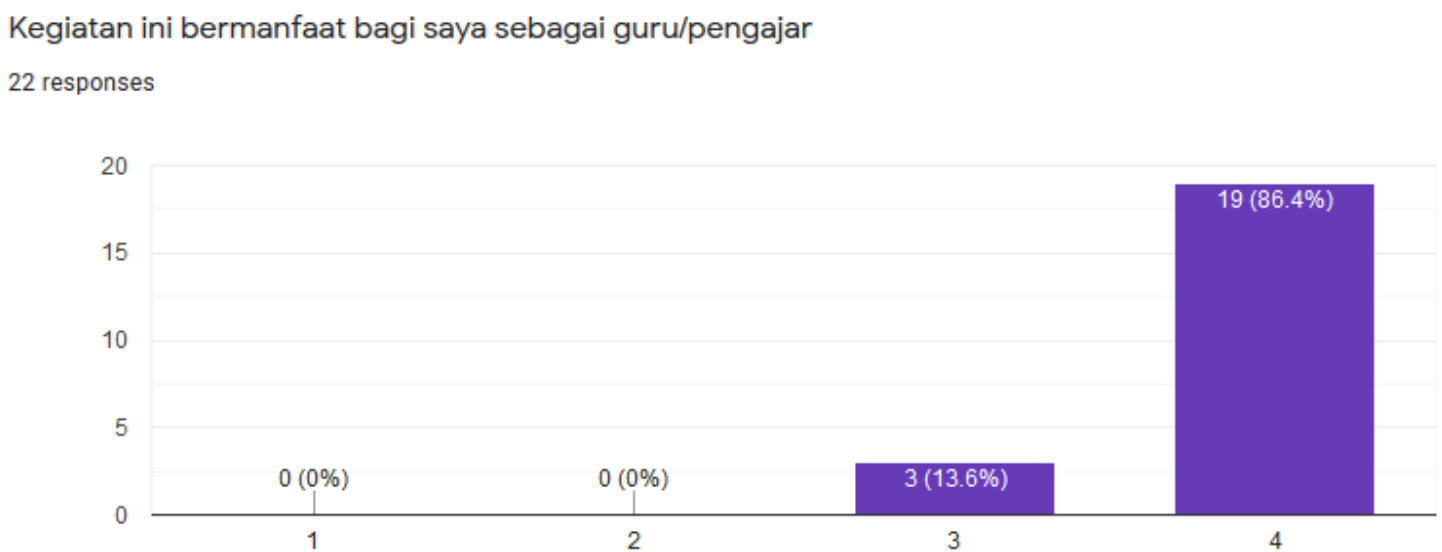

Gambar 5 Kebermanfatan PKM bagi Guru

\section{KESIMPULAN}

Pembelajaran di dalam kelas tidak seharusnya hanya berfokus pada penguasaan materi atau peningkatan kognitif. Peserta didik sekarang dituntut untuk bisa berkolaborasi, berkomunikasi, kreatif, dan berpikir kritis. Semua keterampilan itu masuk dalam daftar keterampilan abad 21 yang harus diinternalisasi dalam proses pembelajaran. Metode $4 \mathrm{C}$ 'S 
memungkinkan guru untuk mengintegrasikan pembelajaran bahasa Inggris dengan berbagai aspek keterampilan tersebut dengan memilih berbagai aktivitas yang menyenangkan dan menantang. Kegiatan PKM ini bertujuan untuk memfasilitasi proses integrase tersebut. Para guru diberikan materi metode 4 C'S sekaligus praktik pembuatan rencana pembelajaran. Kegiatan ini disusun lebih praktis dengan menitikberatkan pada praktik karena diharapkan mampu memberikan dampak yang signifikan pada pembelajaran dikelas. Berdasarkan hasil pengamatan selama kegiatan dan respon peserta pada angket yang diberikan, bisa disimpulkan bahwa para guru senang mengikuti kegiatan ini karena mereka bisa menambah pengetahuan terkait metode pembelajaran, sekaligus parkatik serta sharing rencana pembelajaran yang bisa mereka adopsi atau adaptasi di kelas masing-masing.

\section{UCAPAN TERIMA KASIH}

Ucapan terima kasih kepada seluruh MGMP Bahasa Inggris di Kalimantan Selatan yang telah bersedia menjadi mitra kegiatan serta kepada LP2M Universitas Muhammadiyah Banjarmasin yang telah mendukung PKM ini.

\section{DAFTAR PUSTAKA}

Alawiyah, F. (2013). Peran Guru dalam Kurikulum 2013. Aspirasi, 4(1), 65-74. Retrieved from http://jurnal.dpr.go.id/index.php/aspirasi/article/view/480

Butarbutar, P. E. (2019). Penerapan 4 C'S dalam Pembelajaran Halaman 1 Kompasiana.com. Retrieved June 8, 2020, from https://www.kompasiana.com/poltakbutarbutar8687/5d3fc21a0d8230196b30d912/pene rapan-4-c-s-dalam-pembelajaran?page $=1$

Center, P. P. R. (2010). 21st Century Skills for Students and Teachers. Retrieved from www.21stcenturyskills.com

Nurhidayati, \& Kustini, S. (2018). Pengembangan bahan ajar bahasa inggris berbasis keterampilan abad 21 pada perguruan tinggi vokasi: sebuah kajian literatur. Prosiding Seminar Nasional ASBIS 2019 Politeknik Negeri Banjarmasin, 6014, 417-424.

Rohmadi, M. (2018). Setrategi Dan Inovasi Dalam Pembelajaran Bahasa Dan Sastra Indonesia Di Era Industri 4.0. Pertemuan Ilmiah Bahasa Dan Sastra Indonesia|, 27, $27-40$.

Sukartono. (2017). Revolusi Industri 4.0 dan Dampaknya terhadap Pendidikan di Indonesia. Retrieved from http://fkip.ums.ac.id/wp-content/uploads/sites/43/2018/12/RevolusiIndustri-4.0-dan-Dampaknya-terhadap-Pendidikan-di-Indonesia-Dr.-Sukartono.doc.

Trisnawati, W., \& Sari, A. (2019). INTEGRASI KETERAMPILAN ABAD 21 DALAM MODUL SOCIOLINGUISTICS: KETERAMPILAN 4C (COLLABORATION, COMMUNICATION, CRITICAL THINKING, DAN CREATIVITY). Jurnal Muara Pendidikan, 4(2), 455-466. Retrieved from http://ejournal.stkipmmb.ac.id/index.php/mp/article/view/179

Zubaidah, S. (2018). Mengenal 4C: Learning and Innovation Skills untuk Menghadapi Era Revolusi Industri 4.0. 2nd Science Education National Conference, (April), 1-18. Retrieved from https://www.researchgate.net/publication/332469989_MENGENAL_4C_LEARNING_ AND_INNOVATION_SKILLS_UNTUK_MENGHADAPI_ERA_REVOLUSI_INDU STRI_40_1 
